Please do not remove this page

RMIT

UNIVERSITY

\title{
Gas-sensing characterization of TiO2-ZnO based thin film
}

wisitsoraat, A; Tuantranont, Adisorn; Comini, E.; Sberveglieri, G.; Wlodarski, Wojtek

https://researchrepository.rmit.edu.au/esploro/outputs/9921862682401341/filesAndLinks?institution=61 RMIT_INST\&index=null

wisitsoraat, A., Tuantranont, A., Comini, E., Sberveglieri, G., \& Wlodarski, W. (2006). Gas-sensing characterization of TiO2-ZnO based thin film. 5th IEEE Conference on Sensors, 2006, 964-967. https://doi.org/10.1109/ICSENS.2007.355784

Published Version: https://doi.org/10.1109/ICSENS.2007.355784

Repository homepage: https://researchrepository.rmit.edu.au (C) 2006 IEEE

Downloaded On 2023/04/26 23:31:35 +1000

Please do not remove this page 


\title{
Gas-Sensing Characterization of $\mathrm{TiO}_{2}-\mathrm{ZnO}$ Based Thin Film
}

\author{
A. Wisitsoraat and A. Tuantranont \\ National Electronics and Computer Technology Center \\ 112 Pahol Yothin Rd., Pathumthani THAILAND \\ Email: anurat.wisitsoraat@nectec.or.th
}

\author{
E.Comini and G., Sberveglieri \\ Sensor laboratory, INFM and University of Brescia Via \\ Valotti9, Brescia, ITALY
}

\author{
W. Wlodarski \\ School of Electrical \& Computer Engineering, RMIT University, \\ GPO Box 2476V, Melbourne 3001, Victoria, AUSTRALIA
}

\begin{abstract}
In this work, we investigate gas sensing characteristics of a new composite material, $\mathrm{ZnO}$ doped $\mathrm{TiO}_{2}$. $\mathrm{TiO}_{2} / \mathrm{ZnO}$ layers have been deposited by ion-assisted e-beam evaporation with different doping concentrations. Structural and morphological characterization has been carried out by means of SEM, XRD and EDX in order to correlate structural properties with gas sensing behavior. Gas-sensing characterizations toward acetone, ammonia, ethanol, $\mathrm{CO}$, and $\mathrm{NO}_{2}$ highlight interesting behavior for the layers tested. Low $\mathrm{ZnO}$ concentration $(1 \%)$ increase responses toward acetone and ethanol while response toward $\mathrm{CO}, \mathrm{NO}_{2}$, and ammonia are still low. However, high $\mathrm{ZnO}$ concentration (5-10\%) decreases acetone and ethanol responses while $\mathrm{CO}$, NO, and ammonia is almost diminished. In addition, $\mathrm{ZnO}: \mathrm{TiO}_{2}$ exhibit good response at medium operating temperature of $300{ }^{\circ} \mathrm{C}$.
\end{abstract}

\section{INTRODUCTION}

Titanium dioxide $\left(\mathrm{TiO}_{2}\right)$ and $\mathrm{Zinc}$ oxide $(\mathrm{ZnO})$ are wellknown metal-oxide materials that have promising gassensing properties. $\mathrm{TiO}_{2}$ is a versatile material, which has been used in many applications such as gas sensor, solar cell, photocatalytic layer for self-cleaning glass, optical coating for filters and waveguides, etc. $\mathrm{TiO}_{2}$ is one of the most promising gas-sensing materials due to its high temperature stability, harsh environment tolerance, and catalytic properties. For gas sensing applications, $\mathrm{TiO}_{2}$ is used in anatase phase that has lower resistance and higher response to gas adsorbents that the rutile phase, which is stable at higher temperature. $\mathrm{TiO}_{2}$ nanocrystalline thin films were preferred because of their stable and good gas-sensing characteristics at operating temperatures below $400{ }^{\circ} \mathrm{C}$. However, its low electrical n-type conductivity inhibits its practical implementation as a conductometric sensor. The addition of foreign atoms, such as $\mathrm{Sn} \mathrm{Cr}, \mathrm{Nb}, \mathrm{W}, \mathrm{Mo}$, into $\mathrm{TiO}_{2}$ host has been widely studied to improve its gas sensing behaviors[1-7].
$\mathrm{ZnO}$ is another widely studied gas-sensing and piezoelectric material with interesting behaviors including fast response to a wide variety of gases [8-10]. Nevertheless, its very high working temperature and poor selectivity made $\mathrm{ZnO}$ an unpopular gas sensor. $\mathrm{ZnO}-\mathrm{TiO}_{2}$ should be an interesting mixture for gas sensing material because their useful properties may be collective. However, there is no report on gas sensing study of this combined material.

It is well known that preparation technique can considerably affect the structural and gas sensing properties of the mixed oxide sensors because these peculiarities rely on the essential surface activity of the layers. Electron-beam evaporation is one of preferred techniques for thin film gas sensor fabrication because of doping flexibility, ease of batch fabrication and ability to form high-quality multilayer thin film structures [11-13]. In this work, we investigate gas sensing behaviors of $\mathrm{ZnO}-\mathrm{TiO}_{2}$ thin films prepared by ionassisted electron-beam evaporation with different compositions and the sensors were tested toward various gases, including Ethanol, Ammonia, Acetone, Carbon Monoxide and Nitrogen Dioxide.

\section{MATERIALS AND METHODS}

\section{A. Materials for gas sensor fabrication}

The oxide materials used for the deposition are analytical grade $(99.9 \%) \mathrm{TiO}_{2}$ and $\mathrm{ZnO}$ powders. In this study, they were thoroughly mixed by the weight ratio of $0.9: 0.1$, 0.95:0.05, and 0.99:0.01, respectively. The prepared materials are listed as shown in Table I. For e-beam evaporation, the mixed powder was compressed into cylindrical pellets. The substrates for thin film coating were $200 \mu \mathrm{m}$-thick alumina substrate. Platinum (Pt) is used as the inert material for sensor electrode and thin film heater.

This work has been funded by National Electronic and Computer

Technology Center (NECTEC) of Thailand 
TABLE I. LIST OF THE DIFFERENT MATERIALS PREPARED.

\begin{tabular}{|c|c|c|c|c|c|}
\hline \multirow{2}{*}{$\mathrm{TiO}_{2}$} & \multirow{2}{*}{$\mathrm{ZnO}$} & \multicolumn{4}{|c|}{ Elemental comp. by EDS (at. \%) } \\
\cline { 3 - 6 } & & $\mathrm{Ti}$ & $\mathrm{Zn}$ & $\mathrm{O}$ & $\mathrm{Ti}: \mathrm{Zn}$ \\
\hline $99 \%$ & $1 \%$ & 11.79 & 0.8 & 87.41 & 14.73 \\
\hline $95 \%$ & $5 \%$ & 10.65 & 3.94 & 85.41 & 2.70 \\
\hline $90 \%$ & $10 \%$ & 9.77 & 6.86 & 83.37 & 1.42 \\
\hline
\end{tabular}

\section{B. Gas sensor fabrication}

The gas sensor fabrication process started with the deposition of metal oxide thin film. Prior to deposition, the alumina substrates were cleaned by oxygen-ion bombardment in a vacuum pressure of $\sim 10^{-4}$ Torr. This cleaning was performed to improve adhesion of the film to the substrates by removing moisture and any organic contaminants on the surface. The metal oxide layer was then e-beam evaporated under oxygen-ion beam with an oxygen flow of $25 \mathrm{sccm}$ at a vacuum of $10^{-4}$ Torr. Alumina substrate temperature, deposition rate, and film thickness were $200{ }^{\circ} \mathrm{C}$, $2 \AA / \mathrm{s}$, and $300 \mathrm{~nm}$, respectively. For this study, the depositions were conducted with different $\mathrm{TiO}_{2}-\mathrm{ZnO}$ compositions (Table 1). The films were then annealed inside a furnace under controlled flux of humid synthetic air at 500 ${ }^{\circ} \mathrm{C}$. At this stage, a group of samples was selected in order to examine surface morphology, microstructure, and crystal structure by means of scanning electron microscope (SEM) Energy dispersive X-ray spectroscopy (EDX), and X-ray diffraction (XRD). For the other group of samples, $\mathrm{Pt}$ electrodes were sputtered over the metal oxide layer and substrate through interdigitated shadow masks. Finally, a Pt heater was deposited by sputtering on the backside through shadow masking. For electrical testing, the sensor electrodes and Pt heaters were gold-wire bonded for electrical connection and mounted on a TO8 case.

\section{Gas Sensing Measurements}

The gas-sensing characteristics of metal oxide thin films were characterized toward Ethanol, Ammonia, Acetone, and $\mathrm{CO}$ and $\mathrm{NO}_{2}$. The flow through technique was used to test the gas-sensing properties of thin films. A constant flux of synthetic air of $0.5 \mathrm{l} / \mathrm{min}$ was as gas carrier into which the desired concentration of pollutants - dispersed in synthetic air-was mixed. All measurements were conducted in a temperature-stabilized sealed chamber at $20{ }^{\circ} \mathrm{C}$ under controlled humidity. The Pt-heater was heated by a regulated dc power supply to different operating temperatures. The operating temperature was varied from $200^{\circ} \mathrm{C}$ to $500^{\circ} \mathrm{C}$. The resistances of various sensors were continuously monitored with a computer-controlled system by voltage-amperometric technique with $1 \mathrm{~V} \mathrm{dc}$ bias and current measurement through a picoammeter. The sensor was exposed to a gas sample for $\sim 20$ minutes for each gas response testing and then the air flux was restored.

\section{RESULTS AND DISCUSSION}

\section{A. Microstructural Characteristics}

The chemical compositions of the $\mathrm{TiO}_{2} / \mathrm{ZnO}$ thin films are demonstrated via EDX spectra as shown in Fig. 1. The EDX spectra has been taken on the film deposited on clean $\mathrm{Si}$ substrates. The spectra indicate the presence of $\mathrm{Ti}, \mathrm{Zn}$, and $\mathrm{O}$ elements as expected. The atomic contents of $\mathrm{Ti}, \mathrm{Zn}$, and $\mathrm{O}$ in the thin film have been calculated based on library standard and listed in Table 1. It can be seen that the atomic contents of Ti:Ni in the thin film is in accordance with the content of the source materials prepared from powder mixing. In addition, it can be seen that oxygen content of the film is slightly decrease as $\mathrm{ZnO}$ content increases. However, the oxygen content is far higher than the theoretical values. In fact, this is expected because EDX measurement based on SEM can not provide accurate quantification of light elements such as oxygen, carbon, etc.

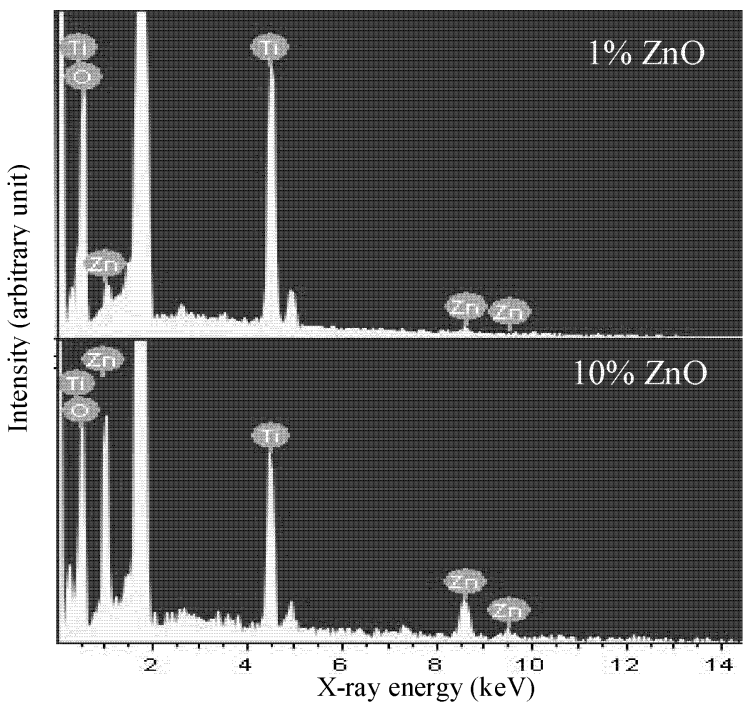

Figure 1. Typical EDX spectra of $\mathrm{TiO}_{2} / \mathrm{ZnO}$ e-beam evaporated thin film after annealing.

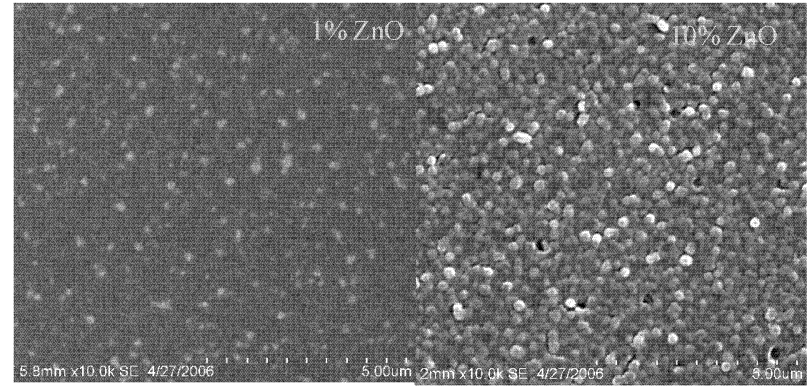

Figure 2. SEM images of $\mathrm{TiO}_{2} / \mathrm{ZnO}$ e-beam evaporated thin film after annealing.

Typical SEM micrographs of $\mathrm{TiO}_{2} / \mathrm{ZnO}$ e-beam evaporated thin films are shown in Fig. 2. It can be seen that the films have sub-micometer grain-size and the grain size tends to increase with $\mathrm{ZnO}$ content. In addition, there are 
brighter particles scattered on the surface. Furthermore, the spotted EDX analysis indicates that these brighter particles have higher $\mathrm{Zn}$ composition. However, EDX spectra can not clearly identify if these particles are $\mathrm{ZnO}$ crystals.

The information on the crystal structure of the mixed oxide thin films are revealed in X-Ray diffractograms as shown in Fig. 3. It can be seen that crystal structure of the films contain the anatase phase of $\mathrm{TiO}_{2}$ with the expected anatase: tetragonal peaks at $25.8^{\circ}, 38.2^{\circ}, 48.5^{\circ}$, and $54.2^{\circ}$. As the $\mathrm{ZnO}$ content increases, the anatase peaks are distorted and reduced in magnitude and a secondary broad peak at around $27.5^{\circ}$ is observed. This unknown peak was found not to match with any forms of $\mathrm{ZnO}$ or $\mathrm{Ti}-\mathrm{Zn}-\mathrm{O}$ compounds. Thus, $\mathrm{ZnO}$ component in the film seems not to form a secondary metal oxide phase in the $\mathrm{TiO}_{2}$ thin film. As a result, the chemical state of $\mathrm{Zn}$ element in the films can not yet be identified.

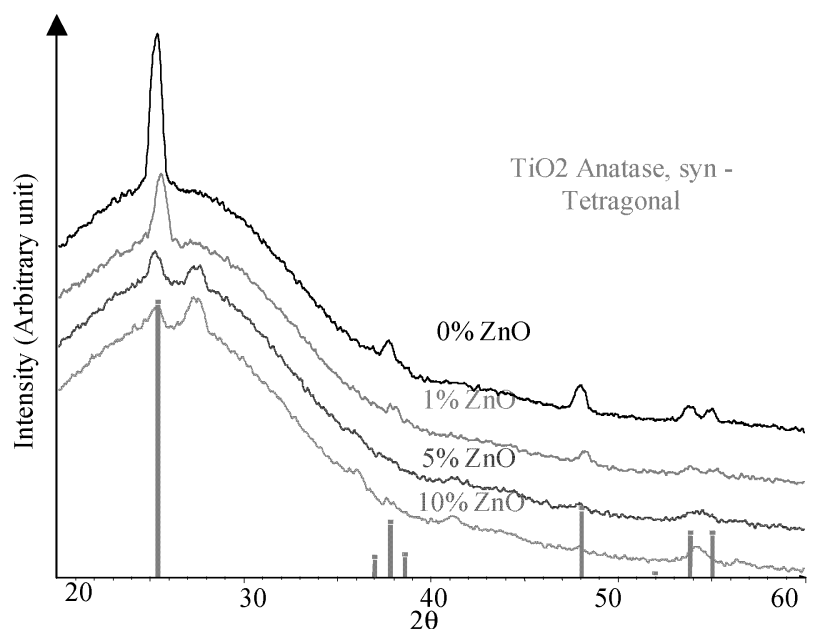

Figure 3. Typical X-Ray diffractograms of e-beam evaporated $\mathrm{TiO}_{2}-\mathrm{ZnO}$ with different $\mathrm{ZnO}$ contents.

\section{B. Gas sensing characteristics}

The gas sensing properties are characterized in term of resistance and gas-sensing response. The resistance of the $\mathrm{TiO}_{2}-\mathrm{ZnO}$ thin films were reduced upon the exposure to reducing gas and increased upon exposure to oxidizing gas, indicating that they are n-type semiconductor. In addition, the resistance of the $\mathrm{TiO}_{2}-\mathrm{ZnO}$ thin films is increased as $\mathrm{ZnO}$ content increases. The gas sensing response of n-type semiconductor gas sensor to a reducing gas is normally defined as the ratio of the resistance change to the resistance with gas sample, $\left(\mathrm{R}_{\mathrm{o}}-\mathrm{R}_{\mathrm{g}}\right) / \mathrm{R}_{0}$, while the response to an oxidizing gas is defined as the ratio of the resistance change to the resistance with no gas sample, $\left(R_{g}-R_{0}\right) / R_{0}$. The gassensing response was calculated from time response data and plotted versus various parameters including gas concentration and temperature. The selected results of gassensing responses of $\mathrm{TiO}_{2}-\mathrm{ZnO}$ e-beam evaporated thin films toward acetone and ethanol are shown in Figs. 4-6.
Fig. 4 shows the acetone response as a function of gas concentration of $\mathrm{TiO}_{2}$ thin film with different $\mathrm{ZnO}$ concentration at $300{ }^{\circ} \mathrm{C}$ operating temperatures. From Fig. 4, it is clear that the inclusion of $\mathrm{ZnO}$ in $\mathrm{TiO}_{2}$ e-beam evaporated thin film leads to considerable deterioration of response to acetone although the resistance of the film is increased. However, it should be noted that low $\mathrm{ZnO}$ concentration (1\%) actually increase responses toward acetone compared to the undoped film.



Figure 4. Dynamic response of $\mathrm{TiO}_{2} / \mathrm{ZnO}$ vs. acetone square pulses at an operating temperature of $300^{\circ} \mathrm{C}$ and $40 \% \mathrm{RH}$

The response to $100 \mathrm{ppm}$ acetone as a function of operating temperature of $\mathrm{TiO}_{2}$ thin film with different $\mathrm{ZnO}$ concentration is shown in Fig. 5. It can be seen that the response to acetone of $\mathrm{TiO}_{2}$ e-beam evaporated thin film is reduced particularly at high operating temperature as the $\mathrm{ZnO}$ content increases. The acetone response is decreased by about an order of magnitude.

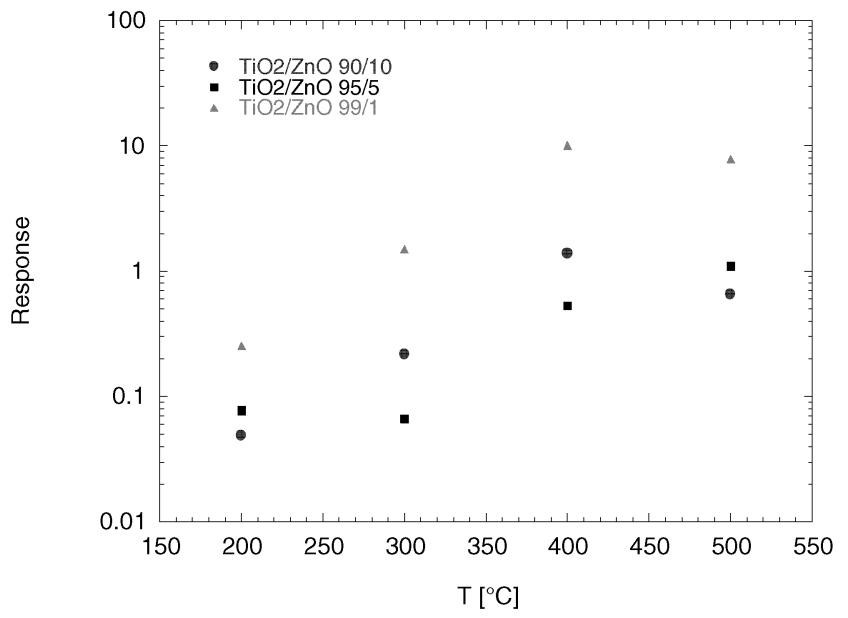

Figure 5. Response to acetone of $\mathrm{TiO} 2 / \mathrm{ZnO}$ vs. operating temperature at $100 \mathrm{ppm}$ concentration.

Fig. 6 illustrates the ethanol response of $\mathrm{TiO}_{2}$ thin film with different $\mathrm{ZnO}$ concentration at $400{ }^{\circ} \mathrm{C}$. From Fig. 6 , it is obvious that the response to ethanol of $\mathrm{TiO}_{2}$ e-beam 
evaporated thin film is also degraded considerably as $\mathrm{ZnO}$ content increases. The response as a function of the concentration follows the well-known power law behavior and the power is decreased by $\mathrm{ZnO}$ addition. Similar to acetone cases, ethanol responses of $\mathrm{TiO}_{2}$ e-beam evaporated thin film is reduced particularly at high operating temperature as $\mathrm{ZnO}$ content increases. In addition, low $\mathrm{ZnO}$ content $\mathrm{TiO}_{2}$ thin film exhibits a maximized response to acetone and ethanol at an operating temperature of $\sim 400^{\circ} \mathrm{C}$.

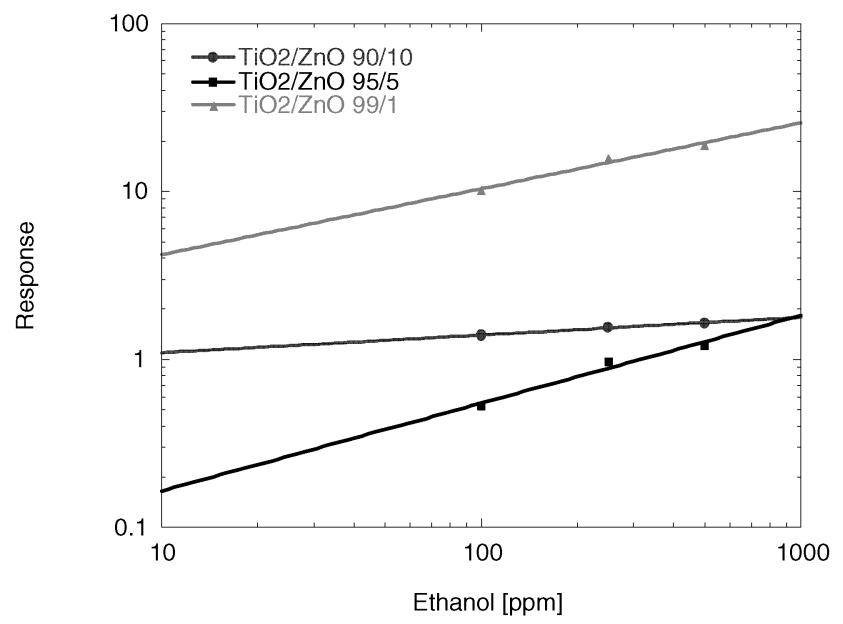

Figure 6. Ethanol response of $\mathrm{TiO}_{2} / \mathrm{ZnO}$ vs. concentration at $400{ }^{\circ} \mathrm{C}$ operating temperature.

On the contrary, the response toward $\mathrm{CO}, \mathrm{NO}_{2}$, and ammonia are found to be very low (less than one) for all $\mathrm{TiO}_{2} / \mathrm{ZnO}$ thin films. In addition, high $\mathrm{ZnO}$ concentration (5$10 \%$ ) nearly diminish the response to these gases. Thus, small $\mathrm{ZnO}$ doping made $\mathrm{TiO}_{2}$ sensor selective to acetone and alcohol vapors while high concentrations of $\mathrm{ZnO}$ seem to be undesirable for gas sensing applications.

The gas-sensing behaviors of $\mathrm{ZnO}$ doped $\mathrm{TiO}_{2}$ thin films should be mainly attributed to the combined changes in surface morphology, chemical composition, and crystal structure modified due to $\mathrm{Zn}$ inclusion. The degradation of gas sensing due to $\mathrm{ZnO}$ addition is unexpected because $\mathrm{ZnO}$ also has good response toward these gases. A possible cause of gas-sensing deterioration may be the increased grain size and distorted $\mathrm{TiO}_{2}$ crystal structure of the combined material. Further study still needs to be done to understand the degradation mechanisms of the $\mathrm{ZnO}$ doped $\mathrm{TiO}_{2}$ thin film.

\section{CONCLUSIONS}

In conclusion, the gas sensing properties of $\mathrm{TiO}_{2}-\mathrm{ZnO}$ composite thin film gas sensor prepared by E-beam evaporation has been investigated toward various gases including acetone, ethanol, ammonia, $\mathrm{CO}$, and $\mathrm{NO}_{2}$. It was found that the sensor's conductance increases as the $\mathrm{Zn}$ content increases. Low $\mathrm{ZnO}$ concentration (1\%) increase responses toward acetone and ethanol while response toward $\mathrm{CO}, \mathrm{NO}_{2}$, and ammonia are very low. However, high $\mathrm{ZnO}$ concentration (5-10\%) decreases the response to all the tested gases. $\mathrm{ZnO}: \mathrm{TiO}_{2}$ exhibit a maximized response to acetone and ethanol at an operating temperature of $\sim 400^{\circ} \mathrm{C}$. Thus, small $\mathrm{ZnO}$ doping made $\mathrm{TiO}_{2}$ sensor selective to acetone and alcohol vapors while high concentrations of $\mathrm{ZnO}$ seem to be undesirable for gas sensing applications.

\section{REFERENCES}

[1] E. Comini, V. Guidi, M. Ferroni, and G., Sberveglieri, "TiO ${ }_{2}$ : Mo, $\mathrm{MoO}_{3}: \mathrm{Ti}, \mathrm{TiO}+\mathrm{WO}_{3}$ and $\mathrm{TiO}: \mathrm{W}$ layer for land fill produced gases sensing," Sens. Actuators B vol. 100, p. 41-46, 2004.

[2] K. Galatsis, Y.X.Li, W. Wlodarski, E.Comini, G., Sberveglieri, C. Cantalini, S. Santucci, and M.Passacantando "Comparison of single and binary oxide $\mathrm{MoO}_{3}, \mathrm{TiO}_{2}$, and $\mathrm{WO}_{3}$ sol-gel gas sensors," Sens. Actuators B vol. 83, p. 276-280, 2002.

[3] I. Jimnez J. Arbiol, G. Dezanneau, A. Cornet and J. R. Morante "Crystalline structure, defects and gas sensor response to NO2 and $\mathrm{H} 2 \mathrm{~S}$ of tungsten trioxide nanopowders" Sensor and Actuator B93 (2003) 475-485.

[4] K. Aguir, C. Lemire, D.B.B. Lollman, "Electrical properties of reactively sputtered $\mathrm{WO}_{3}$ thin films as ozone gas sensor" Sensor and Actuator B84 (2002) 1-5.

[5] H. Tang, K. Prasad, R. Sanjines, and F. Levy. " $\mathrm{TiO}_{2}$ anatase thin film as gas sensors" Sensor and Actuator B26 (1995) 71-75.

[6] K. Zakrzewska, M. Radecka, and M. Rekas, "Effect of Nb, Cr, Sn additions on gas sensing properties of $\mathrm{TiO}_{2}$ thin films" Thin solid film 310 (1997) 161-166.

[7] E. Comini, G., Sberveglieri, and V. Guidi, "Ti-W-O sputtered thin film as n- or p-type gas sensors," Sens. Actuators B 70 (2000) 108114.

[8] H. Xu, X. Liu, D. Cui M. Li and M. Jiang, "A novel method for improving the performance of $\mathrm{ZnO}$ gas sensors," Sens. Actuator B 120 (2005) 123-127.

[9] Y. Anno, T. Maekawa, J. Tamaki, Y. Asano and K. Hayashi, Zincoxide-based semiconductor sensors for detecting acetone and capronaldehyde in the vapor of consommé soup, Sens. Actuators $B$ 24-25 (1995), pp. 623-627.

[10] B. Rao, Zinc oxide ceramic semiconductor gas sensor for ethanol vapor, Mater. Chem. Phys. 64 (2000), pp. 62-65.

[11] T. Oyabu, "Characteristics of $\mathrm{SnO}_{2}$ thin film gas sensor" J. Appl. Phys. 53 (1981) 2785-2787.

[12] H. Madhusudhana and N. Chanodrkar, "Response study of electronbeam evaporated thin-film tin oxide gas sensors" Sensor and Actuator B9 (1992) 1-8.

[13] S. Shukla, S. Seal, L. Ludwig and C. Parish, "Nanocrystalline indium oxide-doped tin oxide thin film as low temperature hydrogen sensor", Sensors and Actuators B, Volume 97, 2004, pp. 256-265. 